IZA DP No. 5497

Occupational Choice, Aggregate Productivity, and Trade

Jürgen Meckl

Benjamin Weigert

February 2011

Forschungsinstitut zur Zukunft der Arbeit Institute for the Study of Labor 


\title{
Occupational Choice, Aggregate Productivity, and Trade
}

\author{
Jürgen Meckl \\ Justus Liebig University Giessen \\ and IZA \\ Benjamin Weigert \\ German Council of Economic Experts
}

\author{
Discussion Paper No. 5497 \\ February 2011
}

IZA

P.O. Box 7240

53072 Bonn

Germany

Phone: +49-228-3894-0

Fax: +49-228-3894-180

E-mail: iza@iza.org

\begin{abstract}
Any opinions expressed here are those of the author(s) and not those of IZA. Research published in this series may include views on policy, but the institute itself takes no institutional policy positions.

The Institute for the Study of Labor (IZA) in Bonn is a local and virtual international research center and a place of communication between science, politics and business. IZA is an independent nonprofit organization supported by Deutsche Post Foundation. The center is associated with the University of Bonn and offers a stimulating research environment through its international network, workshops and conferences, data service, project support, research visits and doctoral program. IZA engages in (i) original and internationally competitive research in all fields of labor economics, (ii) development of policy concepts, and (iii) dissemination of research results and concepts to the interested public.
\end{abstract}

IZA Discussion Papers often represent preliminary work and are circulated to encourage discussion. Citation of such a paper should account for its provisional character. A revised version may be available directly from the author. 
IZA Discussion Paper No. 5497

February 2011

\section{ABSTRACT}

\section{Occupational Choice, Aggregate Productivity, and Trade*}

We propose occupational decisions of heterogeneous individuals as an alternative mechanism of explaining the distribution of firm productivities emphasized by empirical studies. Thus, we integrate the frameworks of Melitz (2003), and of Manasse and Turrini (2001) that establish the theoretical base of trade models with heterogeneous firms. Our model is technically much simpler than the Melitz approach while preserving the main results on firm-selection effects due to international market integration. Our approach paves the way for detailed analysis of institutions in a heterogeneous firm model to better understand the link between institutions and an economy's productivity distribution.

JEL Classification: F12, F16, J24

Keywords: intra-industry trade, heterogeneous productivities, firm selection, occupational choice

Corresponding author:

Jürgen Meckl

Department of Economics

Justus Liebig University Giessen

Licher Str. 66

D-35394 Giessen

Germany

E-mail: juergen.meckl@wirtschaft.uni-giessen.de

\footnotetext{
* The opinions expressed in this paper reflect the personal views of the authors and not necessarily those of the German Council of Economic Experts.
} 


\section{Introduction}

The literature on heterogeneous firms emphasizes the effects of firms' self selection in response to trade liberalization. Three effects are identified as typical reactions to product markets becoming increasingly integrated: (i) highly productive firms that already have been exporting before expand; (ii) additional medium-productive firms will become exporters; (iii) low productive firms exit the market (cf., e.g., Economidou and Murshid, 2008). The most popular theoretical explanation of these firm-selection effects is Melitz (2003). In his model of heterogeneous firms the equilibrium number of active firms is endogenously determined as result of a dynamic market entry game. By entering markets firms make an irreversible investment to discover their specific productivity. After realizing their productivity, a firm decides whether to concentrate on its domestic market, to be active on both national and international markets, or to exit.

Despite its formal elegance and although it constitutes the fundamental base in the literature on heterogeneous-firms trade models (cf. Bernard, Jensen, Redding and Schott, 2007), the application of Melitz's approach is afflicted to the following drawbacks. (i) Due to the complexity of the dynamic market-entry game, Melitz restricts his analysis to steady-state equilibria. This constitutes a severe limitation of his model especially with respect to practical applications of his results (this primarily applies to welfare results). (ii) The assignment of productivities to firms is modeled as a highly abstract process - firms simply draw their productivity from a pool of productivities - that is hardly open to economic interpretation. Additionally, in order to generate a distribution of firm productivities that is in accord with the empirically observations, this distribution of productivities has to be specified appropriately. ${ }^{1}$

The Melitz model has been simplified to alleviate issues resulting from drawback (i). Chaney (2008) and Do and Levchenko (2009), e.g., replace Melitz's modelling of a dynamic market-entry game with an infinite mass of entrants by assuming a fixed number of firms that are either active or inactive. Their simpli-

\footnotetext{
${ }^{1}$ The Melitz model has been successfully extended by introducing specific institutions (Hiep and Hiroshi, 2007) or special characteristics of product markets (Melitz and Ottaviano, 2008; Arkolakis, 2011) or labor markets (Helpman and Itshoki, 2010; Egger and Kreickemeier, 2009). All of these extensions, however, typically postulate a specific distribution of firm productivities in order to reconcile the implications of their models with observed productivity distributions.
} 
fication of the original approach is warranted to allow for introduction of further complexities arising from important economic-geography or political-economy issues. Given that specific focus of their approach, however, tackling problems arising from issue (ii) is dispensable. Our model aims at extending the model along the lines of problem (ii), and it tries to shed light on the process of evolving firm productivities which by construction provides another way so simplify the market entry process in (i). Thus, our contribution is to simplify the Melitz (2003) model in specific a way while at the same time establishing a link between firm productivities and abilities of heterogeneous individuals.

We develop a mechanism explaining the distribution of productivities that is based on the occupational choices of heterogeneous individuals. In doing so, we integrate the models developed by Melitz (2003) and a more restricted predecessor of his approach proposed by Manasse and Turrini (2001) that concentrates only on the exporting decision of an existing mass of firms. We will follow Manasse and Turrini and link firm productivities to abilities of heterogeneous individuals that operate these firms. We extend the Manasse-Turrini approach by endogenizing the number of active firms and an economy's supply of labor by the occupational choice of these individuals. Thereby we preserve the static character of the model and we provide a plausible link between individual innate abilities and firm productivities. As a result, we provide an alternative theoretical foundation to all firm selection effects emphasized by the empirical literature while preserving the simplicity of a static model. Due to this simplicity and its link between firm productivities and productivities of heterogeneous individuals (workers), the model could serve as a framework for a detailed description of the interplay between education and human capital investment, labor market institutions and the resulting distribution of productivities of active firms.

The paper is organized as follows. Section 2 presents the basic model. In section 3 we characterize the equilibrium in a symmetric two-country setting. In section 4 we derive the implications of trade liberalization. Section 5 discusses the relation between the distribution of individual abilities and observed distribution of firm productivities implied by our model. Finally, section 6 concludes with some remarks on possible applications and extensions of our basic framework. 


\section{The Model}

We assume that consumers have preferences over product varieties according to the CES-aggregate

$$
U=\left[\int_{j \in J} c(j)^{\rho} d j\right]^{1 / \rho}, \quad \rho \in(0,1), \quad \sigma \equiv \frac{1}{1-\rho}>1,
$$

where $c(j)$ denotes consumption of product variety $j$, and the measure of set $J$ represents the mass of available goods; $\sigma$ denotes the constant elasticity of substitution between any two goods. Due to the homotheticity of the utility function, we can derive aggregate demand from the problem of a representative consumer. With $E$ denoting aggregate consumer income, demand for variety $i$ is given by

$$
c(i)=\operatorname{Ep}(i)^{-\sigma} P^{\sigma-1} ; \quad P:=\left[\int_{j \in J} p(j)^{1-\sigma} d j\right]^{\frac{1}{1-\sigma}},
$$

where $p(i)$ is the price of variety $i$ and $P$ is the price index defined over prices of varieties.

Production requires the employment of two factors: entrepreneurial or managerial skills and raw labor. The size of a firm is normalized such that one firm employs the skills of one entrepreneur. Entrepreneurs are assumed to be heterogeneous with respect to their skills, and each entrepreneur can employ her skills in the production of at most one variety. Production technology is represented by a cost function with constant marginal costs. As in Melitz (2003), higher productivity is modelled as producing a symmetric product variety at lower variable cost. Hence, a firm's demand for raw labor $l$ is assumed to be linear in its output $x: l=x / q$, where $q$ denotes the firm-specific productivity level. We follow Manasse and Turrini (2001) and assume that the skills of the entrepreneur determines the productivity of the firm; specifically, we assume that a firms productivity $q$ and the entrepreneur's ability $a$ are related by $q=a$. Eventually, each firm faces a residual demand curve with constant elasticity $\sigma$, and a wage rate for raw labor $w$.

The economy is populated by a continuum of individuals of mass $L$. Individuals are heterogeneous with respect to their innate abilities $a$. Abilities are distributed according to some continuous and differentiable density function $g(a)$ with support $[0, \infty)$; the respective distribution function is denoted by $G(a)$. An 
individual with ability $a$ can choose to enter the labor force and supply one unit of raw labor at the wage $w$. Alternatively, an individual can choose to become an entrepreneur and found a firm. In that case her income is her firm's profit. Of course, the wage income of labor is the opportunity cost of becoming an entrepreneur. The self selection of individuals endogenizes the economy's supply of raw labor. In case of $a \in[t, \infty)$ individuals becoming entrepreneurs $(t>0)$, aggregate labor supply is given by $L^{S}(t)=G(t) L$. Consequently, the mass of active domestic firms is given by $M(t)=[1-G(t)] L$.

\section{The Two-Country Equilibrium}

We analyze the interdependence of trade and occupational choice of individuals in a two-country model. As common in the literature on heterogeneous firms, we assume that trade is associated with fixed costs $f_{X}>0$ in order to generate self-selection of firms with respect to exporting. These costs measure exporters' costs to set up and maintain distributional channels in the foreign market. They take the form of output that has to be produced but cannot be sold. Furthermore, we assume that export incurs additional variable costs taking the form of iceberg transportation costs: for one unit of an export good to arrive, $\tau>1$ units have to be produced and shipped. Specifically, we assume $\tau f_{X}^{1 /(\sigma-1)}>1$ for self selection to occur in equilibrium. If this regularity condition holds, profits from exporting are just additional profits for firms that are already active on their domestic market.

In order to simplify the analysis, we follow Melitz (2003) and Manasse and Turrini (2001) and concentrate on the case of two symmetrical countries. Symmetry of both countries allows us to consider the equilibrium allocation and prices in one country. Note that symmetry does not imply that countries are completely identical. Since some firms will only serve their home market while each firm of both countries produces a different variety of the differentiated good, the varieties available to consumers differ between countries. Aggregate variables - wages, aggregate income and expenditures, price indices-, however, will be identical in both countries in equilibrium.

We solve for the equilibrium in our model by deriving a threshold ability $t$ for individuals opening up a firm, and another threshold $s>t$ for domestic firms 
becoming exporters. Individuals with abilities $a<t$ then will supply raw labor.

We first look at the threshold for establishing a firm is determined by profits that accrue from home-market activities. Profit maximization yields markup pricing according to

$$
p(a)=\frac{w}{\rho a} .
$$

Profits from home markets are then given by

$$
\pi(a)=(1-\rho) \frac{w}{\rho} \frac{x(a)}{a} .
$$

An individual with ability $a$ becomes an entrepreneur as her profits from entrepreneurial activities exceed the wage rate. Making use of the clearing of product markets and applying the markup pricing according to (3), we obtain,for given values of $w, E$, and $P$, a unique threshold $t$ :

$$
t=\left(\frac{\sigma-1}{E}\right)^{\frac{1}{\sigma-1}}\left(\frac{w}{\rho}\right)^{\frac{\sigma}{\sigma-1}} P^{-1} .
$$

Having established a firm, exporting is an additional option for the entrepreneur. She will engage in trade if profits from exporting (net of fix costs of exporting) are positive. In order to obtain net profits of a firm with productivity $q=a$ from exporting, let $x_{X}(a)$ denote the export quantity of firm $a$ sold at export price $p_{X}(a)$. Profit maximization for the export activity yields the markup-pricing rule for exports as

$$
p_{X}(a)=\tau \frac{w}{\rho a} .
$$

The corresponding export profits $\pi_{X}$ can be written as:

$$
\pi_{X}(a)=\tau(1-\rho) \frac{w}{\rho} \frac{x_{X}(a)}{a}-w f_{X} .
$$

A firm will now engage in trade if $\pi_{X}(a)$ is non-negative. Applying the marketclearing condition on export markets and making use of the symmetry of the model (identical aggregate variables), we obtain, for given values of $w, E$, and $P$, a unique threshold $s$ for exporting firms:

$$
s=\tau f_{X}^{\frac{1}{\sigma-1}}\left(\frac{\sigma-1}{E}\right)^{\frac{1}{\sigma-1}}\left(\frac{w}{\rho}\right)^{\frac{\sigma}{\sigma-1}} P^{-1} .
$$


Comparing the two threshold conditions (8) and (5), we find that

$$
s=b t, \quad b \equiv \tau f_{X}^{\frac{1}{\sigma-1}} .
$$

Due to our regularity condition, $b>1$ and hence $s>t .^{2}$

In order to solve for the equilibrium, we determine the macroeconomic variables $(w, E, P)$. The mass of domestically produced varieties is given by $M(t)=$ $[1-G(t)] L$ while that of imported varieties amounts to $M(b t)=[1-G(b t)] L$. Thus, the total number of varieties available to consumers is given by $[2-G(t)-$ $G(b t)] L$. For a given threshold value $t$, the price index $P$ containing domestic varieties as well as imported varieties is

$$
\begin{aligned}
P(t) & =L^{\frac{1}{1-\sigma}}\left[\int_{t}^{\infty} p(a)^{1-\sigma} d G(a)+\tau^{1-\sigma} \int_{b t}^{\infty} p(a)^{1-\sigma} d G(a)\right]^{\frac{1}{1-\sigma}} \\
& =\frac{w}{\rho} \frac{L^{\frac{1}{1-\sigma}}}{Q(t)}
\end{aligned}
$$

where

$$
Q(t):=\left[\int_{t}^{\infty} a^{\sigma-1} d G(a)+\tau^{1-\sigma} \int_{b t}^{\infty} a^{\sigma-1} d G(a)\right]^{\frac{1}{\sigma-1}}, \quad Q^{\prime}(t)<0 .
$$

Substituting in (5) by (10) then gives

$$
t=\left[(\sigma-1) \frac{w L}{\rho E}\right]^{\frac{1}{\sigma-1}} Q(t)
$$

We finally have to solve for $w / E$. Aggregate income is made up from aggregate profits and aggregate wages. Aggregate profits comprise profits from domestic sales and from exports. Applying our definitions of the different profits, aggregate profits are given by

$$
\Pi(a, w, \tau, E, P)=(1-\rho) E-w f_{X}[1-G(b t)] L
$$

Adding the wage income of workers $w G(t) L$ and rearranging terms we get

$$
\frac{\rho E}{w L}=G(t)-[1-G(b t)] f_{X} .
$$

\footnotetext{
${ }^{2}$ Melitz applies a similar regularity condition to ensure self-selection of firms. If the regularity condition is not satisfied, all firms export and the threshold for becoming an entrepreneur is determined by $[p(a)-w / a]\left[x(a)+\tau x_{X}(a)\right]=w\left(1+f_{X}\right)$.
} 
Substitution for this term in (11) gives

$$
t=\phi(t):=(\sigma-1)^{\frac{1}{\sigma-1}}\left[G(t)-[1-G(b t)] f_{X}\right]^{\frac{1}{1-\sigma}} Q(t) .
$$

Since $\phi(t)>0$ and $\phi^{\prime}(t)<0$ for all $t \in(0, \infty)$, (13) implies a unique solution $t \in(0, \infty)$. The exporting threshold is then given by $s=b t$. Note that both thresholds $(s, t)$ are functions of the parameters $\left(\tau, f_{X}, \sigma\right)$ while country size is irrelevant for the threshold values. ${ }^{3}$

\section{Impact of Trade Liberalization}

Trade liberalization is interpreted as increased exposure to trade (symmetrical for both countries) and will be modeled as a decline in transportation $\operatorname{costs} \tau$. As shown in the appendix, we get the following results: $d t / d \tau<0$ and $d s / d \tau>0$. As with trade liberalization in the Melitz model, the number of active firms decreases while the number of exporters rises. However, the interpretation of results differ slightly from Melitz. In the present model, fewer individuals choose to become entrepreneurs thereby reducing the number of firms while at the same time aggregate labor employment rises. The intuition for this result is straightforward. As transportation costs decline, the demand for exports rises due to the change in relative prices of the differentiated products. Hence exporting becomes profitable for some firms that only served home markets before, and these firms expand their production. Additionally, incumbent exporters face higher demand and also expand their export production. The resulting additional demand for labor is in parts met by the increase in labor supply as fewer individuals invest in education. Additionally, firms serving only the home markets reduce their production and also compensate for the rise in labor demand.

\section{Distribution of Firm Productivities}

By linking firm productivities to some measure of entrepreneurial abilities our model provides an alternative channel to explain the observed distribution of productivities. Empirical studies (cf., e.g., Del Gatto, Mion and Ottaviano, 2006)

\footnotetext{
${ }^{3}$ Note that Manasse and Turrini (2001) can be interpreted as a special case of our model where $t$ is given exogenously.
} 
find that the distribution of firms' productivities can be reasonably well approximated by a Pareto distribution. Therefore, many extensions or applications of the Melitz model (for an overview see Helpman, 2006) simply postulate productivities to be distributed that way. This is a completely ad-hoc assumption without any deeper foundation. In our model, a reasonable approximation of the distribution of productivities can be traced back to the distribution of the individuals' innate abilities. The literature on psychology established that the distribution of inherent abilities can be well approximated by a normal distribution (cf. Wechsler 1936). Applying that argument to the present model implies the following: As long as the threshold $t$ is sufficiently high (more specifically: as long as $t$ lies to the right of the peak of the distribution, i.e.: as long as not more than half of the workers become entrepreneurs), the normal distribution of abilities generates a reasonably well approximation to the observed distribution of productivities. This result holds even if firm productivity and entrepreneurial abilities are not related 1 to 1 , as assumed in the above analysis of the model, but by some monotonically increasing function; the latter may be important if abilities are transformed into productivities by education (see below). As a result, our approach allows to substitute for the ad-hoc assumption of Pareto-distributed productivities in the market-entry game by an empirically well approved assumption about the distribution of abilities.

\section{Conclusions}

This paper has developed an alternative mechanism of explaining the distribution of productivities across firms and their self-selection with respect to export activities. The mechanism is based on the occupational choices of heterogeneous individuals. Thus, we integrate the models developed by Manasse and Turrini (2001) and by Melitz (2003). The analysis has shown that the impact of trade liberalization on the self-selection of firms is robust with respect to the source of firms' productivity differentials.

Our main contribution is to simplify the analytical framework of Melitz type models by reducing it to a static model. With respect to assigning productivities to firms we substitute for Melitz's very abstract lottery with firms drawing productivities randomly from an arbitrarily specified distribution of productivities by 
an economically intuitive explanation of the emergence of persistent productivity differentials. In this end, we provide a plausible foundation for the observed distribution of firm productivities that grounds on the distribution of innate abilities of individuals.

By reducing the Melitz model to a static model a number of important extension to the model are possible without making it analytically intractable. Due to its analytical simplicity, our model provides a convenient framework for integration of labor-market imperfections into heterogeneous-firms models (cf. Egger and Kreickemeier, 2008). Because of its static character, the model allows for a more comprehensive interpretation of welfare results from trade liberalization that is not limited to steady states (cf. Baldwin and Forslid, 2010). On the other hand, the model opens up the possibility of analyzing the link between endogenous growth and trade liberalization based on q-theory approaches (cf. Baldwin and Forslid, 2000, or Albert and Meckl, 1998).

Eventually, the model can be easily extended to include important institutional aspects affecting the distribution of productivities and thus a country's average productivity. Instead of a simple linear relationship between productivities and innate abilities one may explicitly introduce institutions by modeling a relationship $q=F(a ; I)$ between firm productivities and innate abilities as well as an economy's institutional frame work $I$. This will pave the way for an analysis of policies manipulating the distribution of productivities by educational policies, such as educational subsidies or improvements in the educational technology. Eventually, we can trace back the differences in productivities - and hence comparative advantage (cf. Bernard, Redding and Schott, 2007) - to differences in the quality of labor inputs and thus on institutional differences in national educational systems. As indicated by empirical analyses of augmented neoclassical trade models (cf. Trefler, 1995), such quality differences are important in understanding trade patterns. However, institutional differences are not limited to the productivity generating mechanism but may also include industrial policies interacting with entrepreneurial decision of individuals. 


\section{References}

Albert, M., Meckl, J., 1998. Qualitatively Rational Expectations and Adjustment in the Specific-Factors Model. Review of International Economics 6, 670-682.

Arkolakis, C., 2011. Market Penetration Costs and the New Consumers Margin in International Trade. Journal of Political Economy, forthcoming.

Baldwin, R.E., Forslid, R., 2000. Trade Liberalization and Endogenous Growth. Journal of International Economics 50, 497-517.

Baldwin, R.E., Forslid, R., 2010. Trade Liberalization with Heterogeneous Firms. Review of Development Economics 14, 161-176.

Bernard, A.B., Jensen, J.B, Redding, S.J., Schott, P.K., 2007. Firms in International Trade. Journal of Economic Perspectives 21, 105-130.

Bernard, A.B., Redding, S.J., Schott, P.K., 2007. Comparative Advantage and Heterogeneous Firms. Review of Economic Studies 74, 31-66.

Chaney, T., 2008. Distorted Gravity: The Intensive and Extensive Margins of International Trade. American Economic Review 98, 1707-1721.

Del Gatto, M., Mion, G., Ottaviano, G.I.P., 2006. Trade Integration, Firm Selection and the Costs of Non-Europe. CEPR Discussion Paper 5730.

Do, Q.-T., Levchenko, A.A., 2009. Trade, Inequality, and the Political Economy of Institutions. Journal of Economic Theory 144, 1489-1520.

Economidou C., Murshid, A.P., 2008. Testing the Linkages between Trade and Productivity Growth. Review of Development Economics, 12, 845-860

Egger, H. and Kreickemeier, U., 2008. Fairness, Trade, and Inequality. CESifo Working Paper No. 2344.

Egger, H. and Kreickemeier, U., 2009. Firm Heterogeneity and the Labour Market Effects of Trade Liberalization. International Economic Review 50, 187216.

Helpman, E., 2006. Trade, FDI, and the Organization of Firms. Journal of Economic Literature XLIV, 589-630.

Helpman, E., 2006., Itskhoki, O., 2010. Labor Market Rigidities, Trade and Unemployment. Review of Economic Studies 77, 1100-1137.

Hiep, N., Hiroshi, O., 2007. Efficiency in International Trade with Firm Heterogeneity and Networks. Review of Development Economics 11, 217-231.

Manasse, P., Turrini, A., 2001. Trade, Wages, and 'Superstars'. Journal of International Economics 54, 97-117. 
Melitz, M.J., 2003. The Impact of Trade on Intra-Industry Reallocations and Aggregate Industry Productivity. Econometrica 71, 1695-1725.

Melitz, M.J., Ottaviano, G.I.P., 2008. Market Size, Trade, and Productivity. Review of Economic Studies 75, 295-316.

Trefler, D., 1995. The Case of the Missing Trade and other Mysteries. American Economic Review 85, 1029-1046.

Wechsler, D., 1936. Measurement of Adult Intelligence. Williams \& Wilkins: Baltimore.

\section{Appendix}

The appendix contains details of the comparative-static analysis of our twocountry model. We apply the following two-equation description of the equilibrium to derive the comparative-static effects of a change in $\tau$ :

$$
\begin{aligned}
& Y_{1}(s, t, \tau):=t-(\sigma-1)^{\frac{1}{\sigma-1}} A(s, t) Z(s, t, \tau)=0 \\
& Y_{2}(s, t, \tau):=s-\tau f_{X}^{\frac{1}{\sigma-1}}(\sigma-1)^{\frac{1}{\sigma-1}} A(s, t) Z(s, t, \tau)=0,
\end{aligned}
$$

where

$$
A(s, t):=\left[G(t)-[1-G(s)] f_{X}\right]^{\frac{1}{1-\sigma}}
$$

and

$$
Z(s, t, \tau):=\left[\int_{t}^{\infty} a^{\sigma-1} d G(a)+\tau^{1-\sigma} \int_{s}^{\infty} a^{\sigma-1} d G(a)\right]^{\frac{1}{\sigma-1}} .
$$

The partial derivatives of the functions $A$ and $Z$ are given by:

$$
\begin{gathered}
\frac{\partial A}{\partial t}=\frac{A^{\sigma}}{1-\sigma} g(t)<0, \quad \frac{\partial A}{\partial s}=\frac{A^{\sigma}}{1-\sigma} g(s) f_{X}<0, \\
\frac{\partial Z}{\partial t}=-\frac{Z^{2-\sigma}}{\sigma-1} t^{\sigma-1} g(t)<0, \quad \frac{\partial Z}{\partial s}=-\frac{Z^{2-\sigma}}{\sigma-1} s^{\sigma-1} g(s)<0, \\
\frac{\partial Z}{\partial \tau}=-Z^{2-\sigma} \tau^{-\sigma} \int_{s}^{\infty} a^{\sigma-1} d G(a)<0 .
\end{gathered}
$$

Since all partial derivatives of $A$ and $Z$ with respect to the thresholds $(s, t)$ are negative, the derivatives of the product of both functions must be negative as well. This implies

$$
\frac{\partial Y_{1}}{\partial s}=t z_{1}>0, \quad \frac{\partial Y_{1}}{\partial t}=1+t z_{2}>0, \quad \frac{\partial Y_{2}}{\partial s}=1+s z_{1}>0, \quad \frac{\partial Y_{2}}{\partial t}=s z_{2}>0,
$$


where

$$
z_{1}:=-\left[\frac{\partial A}{\partial s} \frac{1}{A}+\frac{\partial Z}{\partial s} \frac{1}{Z}\right]>0, \quad z_{2}:=-\left[\frac{\partial A}{\partial t} \frac{1}{A}+\frac{\partial Z}{\partial t} \frac{1}{Z}\right]>0 .
$$

Finally, the partial derivatives of the functions $Y_{1}$ and $Y_{2}$ with respect to $\tau$ are:

$$
\begin{aligned}
& \frac{\partial Y_{1}}{\partial \tau}=-(\sigma-1)^{\frac{1}{\sigma-1}} A \frac{\partial Z}{\partial \tau}>0 \\
& \frac{\partial Y_{2}}{\partial \tau}=\frac{s}{\tau}\left[\tau^{1-\sigma} Z^{1-\sigma} \int_{s}^{\infty} a^{\sigma-1} d G(a)-1\right]<0,
\end{aligned}
$$

where $\partial Y_{1} / \partial \tau<0$ follows from $\tau^{1-\sigma} \int_{s}^{\infty} a^{\sigma-1} d G(a)<Z^{\sigma-1}$.

The Jacobian $J$ of the system (A.1)-(A.2) is given by:

$$
J=\left[\begin{array}{ll}
\frac{\partial Y_{1}}{\partial s} & \frac{\partial Y_{1}}{\partial t} \\
\frac{\partial Y_{2}}{\partial s} & \frac{\partial Y_{2}}{\partial t}
\end{array}\right]
$$

with

$$
|J|=\frac{\partial Y_{1}}{\partial s} \frac{\partial Y_{2}}{\partial t}-\frac{\partial Y_{2}}{\partial s} \frac{\partial Y_{1}}{\partial t}<0 .
$$

In order to proof $|J|<0$, we rewrite this condition as

$$
\frac{\partial Y_{1} / \partial s}{\partial Y_{1} / \partial t}<\frac{\partial Y_{2} / \partial s}{\partial Y_{2} / \partial t}
$$

Making use of (A.3) this can be written as

$$
\frac{z_{1}}{\frac{1}{t}+z_{2}}<\frac{\frac{1}{s}+z_{1}}{z_{2}}
$$

The inequality follows from $z_{1}<1 / s+z_{1}$ and $1 / t+z_{2}>z_{2}$.

The impact of a change in $\tau$ on the equilibrium values of $t$ and $s$ can now be calculated as

$$
\begin{aligned}
\frac{d s}{d \tau} & =-\frac{\frac{\partial Y_{1}}{\partial \tau} \frac{\partial Y_{2}}{\partial t}-\frac{\partial Y_{2}}{\partial \tau} \frac{\partial Y_{1}}{\partial t}}{|J|}>0 \\
\frac{d t}{d \tau} & =-\frac{\frac{\partial Y_{1}}{\partial s} \frac{\partial Y_{2}}{\partial \tau}-\frac{\partial Y_{2}}{\partial s} \frac{\partial Y_{1}}{\partial \tau}}{|J|}<0
\end{aligned}
$$

The signs are determined by (A.3)-(A.6). 